\title{
Relationship of adiponectin to body fat distribution, insulin sensitivity and plasma lipoproteins: evidence for independent roles of age and sex
}

\author{
M. Cnop ${ }^{1,5}$, P. J. Havel ${ }^{2}$, K. M. Utzschneider ${ }^{1}$, D. B. Carr $^{3}$, M. K. Sinha ${ }^{4}$, E. J. Boyko ${ }^{1}$, B. M. Retzlaff ${ }^{1}$, \\ R. H. Knopp ${ }^{1}$, J. D. Brunzell ${ }^{1}$, S. E. Kahn ${ }^{1}$ \\ ${ }^{1}$ Division of Metabolism, Endocrinology and Nutrition, Department of Medicine, \\ Veterans Affairs Puget Sound Health Care System (151) and University of Washington, Seattle, USA \\ 2 Department of Nutrition, University of California, Davis, CA, USA \\ ${ }^{3}$ Department of Obstetrics and Gynecology, University of Washington, USA \\ ${ }^{4}$ Linco Research Inc., St. Charles, MO, USA \\ ${ }^{5}$ Laboratory of Experimental Medicine and Division of Endocrinology, Université Libre de Bruxelles, Brussels, Belgium
}

\section{Abstract}

Aims/hypothesis. Increased intra-abdominal fat is associated with insulin resistance and an atherogenic lipoprotein profile. Circulating concentrations of adiponectin, an adipocyte-derived protein, are decreased with insulin resistance. We investigated the relationships between adiponectin and leptin, body fat distribution, insulin sensitivity and lipoproteins.

Methods. We measured plasma adiponectin, leptin and lipid concentrations, intra-abdominal and subcutaneous fat areas by CT scan, and insulin sensitivity index $\left(\mathrm{S}_{\mathrm{I}}\right)$ in 182 subjects $(76 \mathrm{M} / 106 \mathrm{~F})$.

Results. Adiponectin concentrations were higher in women than in men $(7.4 \pm 2.9$ vs $5.4 \pm 2.3 \mu \mathrm{g} / \mathrm{ml}$, $p<0.0001)$ as were leptin concentrations $(19.1 \pm 13.7$ vs $6.9 \pm 5.1 \mathrm{ng} / \mathrm{ml}, p<0.0001)$. Women were more insulin sensitive $\left(\mathrm{S}_{\mathrm{I}}: 6.8 \pm 3.9\right.$ vs $5.9 \pm 4.4 \times 10^{-5} \mathrm{~min}^{-1} /(\mathrm{pmol} / \mathrm{l})$, $p<0.01)$ and had more subcutaneous $(240 \pm 133$ vs $187 \pm 90 \mathrm{~cm}^{2}, p<0.01$ ), but less intra-abdominal fat (82 \pm 57 vs $\left.124 \pm 68 \mathrm{~cm}^{2}, p<0.0001\right)$. By simple regression, adiponectin was positively correlated with age $(r=0.227, p<0.01)$ and $\mathrm{S}_{\mathrm{I}}(r=0.375, p<0.0001)$, and nega- tively correlated with BMI $(r=-0.333, p<0.0001)$, subcutaneous $(r=-0.168, p<0.05)$ and intra-abdominal fat $(r=-0.35, p<0.0001)$. Adiponectin was negatively correlated with triglycerides $(r=-0.281, p<0.001)$ and positively correlated with HDL cholesterol $(r=0.605$, $p<0.0001)$ and $\mathrm{Rf}$, a measure of LDL particle buoyancy $(r=0.474, p<0.0001)$. By multiple regression analysis, adiponectin was related to age $(p<0.0001)$, sex $(p<0.005)$ and intra-abdominal fat $(p<0.01)$. $\mathrm{S}_{\mathrm{I}}$ was related to intraabdominal fat $(p<0.0001)$ and adiponectin $(p<0.0005)$. Both intra-abdominal fat and adiponectin contributed independently to triglycerides, HDL cholesterol and Rf. Conclusion/interpretation. These data suggest that adiponectin concentrations are determined by intra-abdominal fat mass, with additional independent effects of age and sex. Adiponectin could link intra-abdominal fat with insulin resistance and an atherogenic lipoprotein profile. [Diabetologia (2003) 46:459-469]

Keywords Adiponectin, Acrp30, adipoQ, central obesity, subcutaneous fat, intra-abdominal fat, insulin sensitivity, lipids, hepatic lipase, cardiovascular disease, leptin.
Received: 25 September 2002 / Revised: 10 December 2002

Published online: 10 April 2003

(C) Springer-Verlag 2003

Corresponding author: S. E. Kahn MB ChB, Division of Metabolism, Endocrinology and Nutrition, Department of Medicine, Veterans Affairs Puget Sound Health Care System (151) and University of Washington, 1660 S. Columbian Way, Seattle, WA 98108 USA

E-mail: skahn@u.washington.edu

Abbreviations: $\mathrm{S}_{\mathrm{I}}$, insulin sensitivity index; IAF, intra-abdominal fat; SCF, subcutaneous fat; CT, computed tomography; DGUC, density gradient ultracentrifugation; TNF- $\alpha$, tumor necrosis factor- $\alpha$; apoB, apolipoprotein B.
It is well recognized that obesity and insulin resistance are closely related $[1,2,3,4]$. Android body fat distribution is associated with insulin resistance more than is a gynoid body fat distribution [5], with the site of abdominal fat distribution being an additional determinant of insulin sensitivity $[6,7,8,9,10,11]$. We found in both lean and obese subjects that the intraabdominal fat (IAF) depot is a stronger determinant of insulin sensitivity than the subcutaneous fat (SCF) depot [11], while SCF is the main determinant of the plasma concentration of leptin [11], an adipocyte-derived hormone regulating energy metabolism $[12,13]$. 
There is great interest in the relationship between body fat distribution and insulin sensitivity due to their role in cardiovascular disease and Type 2 diabetes, but the mediators of this interaction between body fat and insulin sensitivity remain uncertain. A role has been suggested for NEFA as they are commonly increased in states associated with insulin resistance $[14,15,16]$ and induce insulin resistance in vivo and in vitro $[15,16]$. The lipolytically more active intra-abdominal fat [17] is an important source of NEFA in the portal circulation, draining them directly to the liver and thereby altering hepatic glucose and lipid metabolism [18, 19, 20]. Recently, it has been shown in mice fed a high fat, high sucrose diet that administration of the recently characterized adipocyte secreted protein adiponectin increases fat oxidation, thereby reducing NEFA concentrations and body weight [21].

Adiponectin, also known as apM1 [22], Acrp30 [23], GBP28 [24] or adipoQ [25], has been suggested to be an important regulator of insulin action, thereby possibly linking adiposity and insulin sensitivity [26, 27]. Unlike many of the other "adipokines" such as tumour necrosis factor- $\alpha$ (TNF- $\alpha)$, leptin and resistin that increase with adiposity [13], circulating adiponectin concentrations are reduced in individuals who are obese [28, 29, 30, 31], have cardiovascular disease [32] or Type 2 diabetes [29]. Circulating adiponectin concentrations are correlated with insulin sensitivity $[30,31]$, with low concentrations predicting a future decrease in insulin sensitivity in Pima Indians [33]. Furthermore, low adiponectin concentrations have been associated with a more atherogenic lipid profile [34] and have been shown to increase with thiazolidinedione administration [35, 36]. Studies in animals also suggest that adiponectin could be an important determinant of insulin action. Thus, a decline in adiponectin concentrations has been shown to coincide with the development of hyperinsulinaemia and insulin resistance in obese rhesus monkeys [37] while both heterozygous and homozygous adiponectin null mice have a phenotype of insulin resistance with a gene dose effect [38] and develop marked diet-induced insulin resistance [39].

Based on these observations, we hypothesized that central adiposity and specifically visceral adiposity is an important determinant of adiponectin and could be important in linking adiposity to insulin sensitivity. Therefore, we examined the relationships of adiponectin concentrations with insulin sensitivity, body fat distribution and lipids in a large cohort of apparently healthy human subjects in whom we have rigorously quantified these parameters. The questions we posed were the following: (i) Are adiponectin concentrations related to body fat distribution and if so, is one abdominal fat depot more strongly related to adiponectin than another? (ii) Are adiponectin concentrations related to an atherogenic lipid profile and if so, to which lipoprotein measure? (iii) Do age and sex have an impact on these relationships?

\section{Subjects and Methods}

Subjects. We recruited 182 individuals (76 men/106 women) aged 32 to 75 years by advertisement, from the Greater Seattle area, to participate in a study on the effect of insulin sensitivity on the lipoprotein profile response to egg consumption [40]. Eligible subjects had to be apparently healthy with no known history of diabetes, coronary artery disease or other vascular disease. In addition, they could not be receiving treatment for lipid disorders or hypertension and had to be free of renal or hepatic disease. At the time of screening, qualifying individuals had to have a fasting plasma glucose less than $6.4 \mathrm{mmol} / \mathrm{l}$, LDL cholesterol less than $4.9 \mathrm{mmol} / \mathrm{l}$ and triglycerides less than $5.7 \mathrm{mmol} / \mathrm{l}$. The study was reviewed and approved by the Human Subjects Review Committee at the University of Washington and written informed consent was obtained from all subjects. All data shown in this analysis are baseline measurements carried out at the start of the study.

Characterization of body size and fat distribution. Body mass index (BMI) was calculated as weight $(\mathrm{kg}) /[\text { height }(\mathrm{m})]^{2}$. The waist-to-hip ratio was calculated as waist circumference $(\mathrm{cm}) /$ hip circumference $(\mathrm{cm})[41]$.

A computed tomography (CT) scan at the level of the umbilicus was used to quantify SCF and IAF areas [42]. For this purpose, the border of the intra-abdominal cavity was outlined on the CT image and total fat and IAF areas were quantified by selecting an attenuation range of -250 to -50 Hounsfield units. SCF area was calculated as the difference between total fat area and IAF area. The variability of these measures made by a single observer is $1.5 \%$ and day to day variability is less than $1 \%[43]$.

Insulin sensitivity. Insulin sensitivity was quantified as the insulin sensitivity index $\left(\mathrm{S}_{\mathrm{I}}\right)$ using Bergman's minimal model of glucose kinetics [44]. For this purpose, the glucose and insulin data obtained during a frequently sampled intravenous glucose tolerance test modified by the injection of tolbutamide were analyzed $[45,46]$. The day to day variability of $S_{I}$ in our laboratory is $16.9 \%$ [47].

Chemical analyses. All analyses were carried out on blood samples drawn after an overnight fast of at least $12 \mathrm{~h}$ and were stored at $-70^{\circ} \mathrm{C}$ until assayed. All samples were then measured in duplicate in each assay. Plasma glucose concentrations were measured using the glucose oxidase method. Immunoreactive insulin concentrations were measured in plasma by radioimmunoassay using a modification of a double antibody method [48]. Plasma leptin concentrations were also measured by radioimmunoassay (Linco Research, St. Louis Mo., USA) [49].

Plasma adiponectin concentrations were measured using a radioimmunoassay for human adiponectin (Linco Research). The assay utilizes ${ }^{125} \mathrm{I}$-labelled adiponectin and an anti-adiponectin rabbit antiserum to measure adiponectin concentrations by the double antibody/PEG technique. Standards over the range of 1 to $200 \mathrm{ng} / \mathrm{ml}$ were prepared using recombinant human adiponectin. All plasma samples were diluted 1:200 yielding an effective range of 0.2 to $40 \mu \mathrm{g} / \mathrm{ml}$. The intra-assay and inter-assay coefficients of variation at adiponectin concentrations in the range of 3 to $15 \mu \mathrm{g} / \mathrm{ml}$ are 1.8 to $6.2 \%$ and 6.9 to $9.3 \%$, respectively. Plasma adiponectin concentrations measured in 40 paired samples using this assay and ELISA [28] 
were similar $(10.4 \pm 6.6 \mathrm{vs} 10.1 \pm 5.5 \mu \mathrm{g} / \mathrm{ml})$ and linearly related ( $r=0.896, p<0.0001$; M.K. Sinha, unpublished observation).

Plasma triglycerides and total cholesterol were measured by enzymatic analytical chemistry. HDL cholesterol was precipitated using dextran-sulphate and measured enzymatically. The LDL cholesterol concentration was calculated using the Friedewald equation: LDL cholesterol=total cholesterol-HDL cholesterol-(triglycerides/5). Apolipoprotein B (apoB) was measured by nephelometry [50] and non-equilibrium density gradient ultracentrifugation (DGUC) was carried out with the collection of 38 fractions in which cholesterol was measured [51]. The LDL relative flotation index (Rf), a measure of LDL particle buoyancy, was measured by dividing the fraction number containing the highest LDL cholesterol concentration by 38 , the latter representing the total number of fractions sampled. Lipoprotein measures were carried out in only 170 subjects with $\mathrm{Rf}$ not being measured in an additional eight individuals.

Statistical analyses. Data are expressed as means \pm SD. Normality of distribution of the data was tested by the Kolmogorov-Smirnov test, a $p$ value greater than 0.05 indicated that the observed distribution of a variable is not statistically different from the normal distribution. Comparison of demographic and metabolic variables by sex was done by unpaired $t$ test and by Mann-Whitney U test when the data were not normally distributed. The relative contribution of age, sex and abdominal fat compartments was examined by analyses of subgroups of men and women and of young and older subjects. These subject groups were matched for IAF by pairwise selection of individuals with IAF differing by less than or equal to $10 \mathrm{~cm}^{2}$ and were then compared by unpaired $t$ tests or Mann-Whitney $\mathrm{U}$ tests.

Scatterplots were used to visually evaluate the relationships between continuous variables in the whole cohort of $182 \mathrm{sub}$ jects and when subdivided by sex. Correlations were done by linear regression. Multiple regression analysis was used to determine whether the association between the dependent and independent variables of interest remained significant after adjusting for other potentially confounding independent variables. For this analysis, the dependent variables were natural $\log \left(\log _{\mathrm{e}}\right)$ transformed if they were not normally distributed to satisfy the necessary statistical assumptions of linear regression. Stepwise model building was used to estimate the relative contribution of the independent variables and the variability of the dependent variable. Data with a $p$ value less than or equal to 0.05 were considered statistically significant.

\section{Results}

Demographic and phenotypic characteristics. The subjects (Table 1) had broad ranges for age, BMI and insulin sensitivity (Fig. 1, 2, 3). Plasma measurements of insulin, leptin, adiponectin and lipids had a broad range, while glucose was more limited as diabetic subjects were excluded from the study (Table 1).

Men and women were well matched for age and BMI but differed in their distribution of body fat. Men had a greater waist-to-hip ratio and more IAF but less SCF. In addition, in men insulin sensitivity was lower, glucose was higher, and both leptin and adiponectin

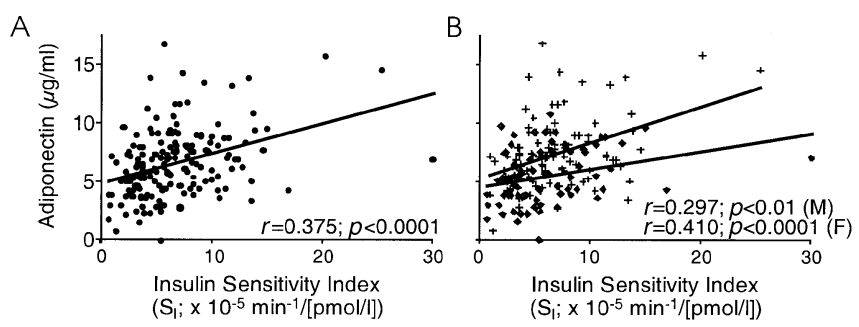

Fig. 1A, B. Relationship between adiponectin concentrations and insulin sensitivity in 182 subjects (A). The linear correlation between these two variables is maintained when subjects are subdivided based on sex [76 men (filled diamonds)/106 women (crosses)] (B)

Table 1. Age, body fat distribution, metabolic characteristics and lipoprotein measurement

\begin{tabular}{|c|c|c|c|}
\hline$n$ & 182 & 76 & 106 \\
\hline Age (y) & $52.5 \pm 9.9$ & $52.7 \pm 10.4$ & $52.4 \pm 9.7$ \\
\hline Waist-to-hip ratio & $0.84 \pm 0.09$ & $0.92 \pm 0.06$ & $0.78 \pm 0.06 * *$ \\
\hline $\mathrm{SCF}$ area $\left(\mathrm{cm}^{2}\right)$ & $218 \pm 119$ & $187 \pm 90$ & $240 \pm 133 *$ \\
\hline IAF area $\left(\mathrm{cm}^{2}\right)$ & $100 \pm 65$ & $124 \pm 68$ & $82 \pm 57 * *$ \\
\hline Insulin (pmol/l) & $63.8 \pm 43.7$ & $67.8 \pm 49.1$ & $60.9 \pm 39.4$ \\
\hline Leptin $(\mathrm{ng} / \mathrm{ml})$ & $14.0 \pm 12.5$ & $6.9 \pm 5.1$ & $19.1 \pm 13.7 * *$ \\
\hline Adiponectin $(\mu \mathrm{g} / \mathrm{ml})$ & $6.6 \pm 2.8$ & $5.4 \pm 2.3$ & $7.4 \pm 2.9 * *$ \\
\hline Triglycerides (mmol/l) & $1.39 \pm 0.87$ & $1.42 \pm 1.0$ & $1.36 \pm 0.78$ \\
\hline HDL cholesterol (mmol/l) & $1.34 \pm 0.36$ & $1.15 \pm 0.24$ & $1.48 \pm 0.36 * *$ \\
\hline
\end{tabular}

Data are means \pm SD

$* p<0.05, * * p<0.001$ versus men.

Lipoprotein measurements were not available in 12 subjects with Rf not being available in an additional 8 individuals 

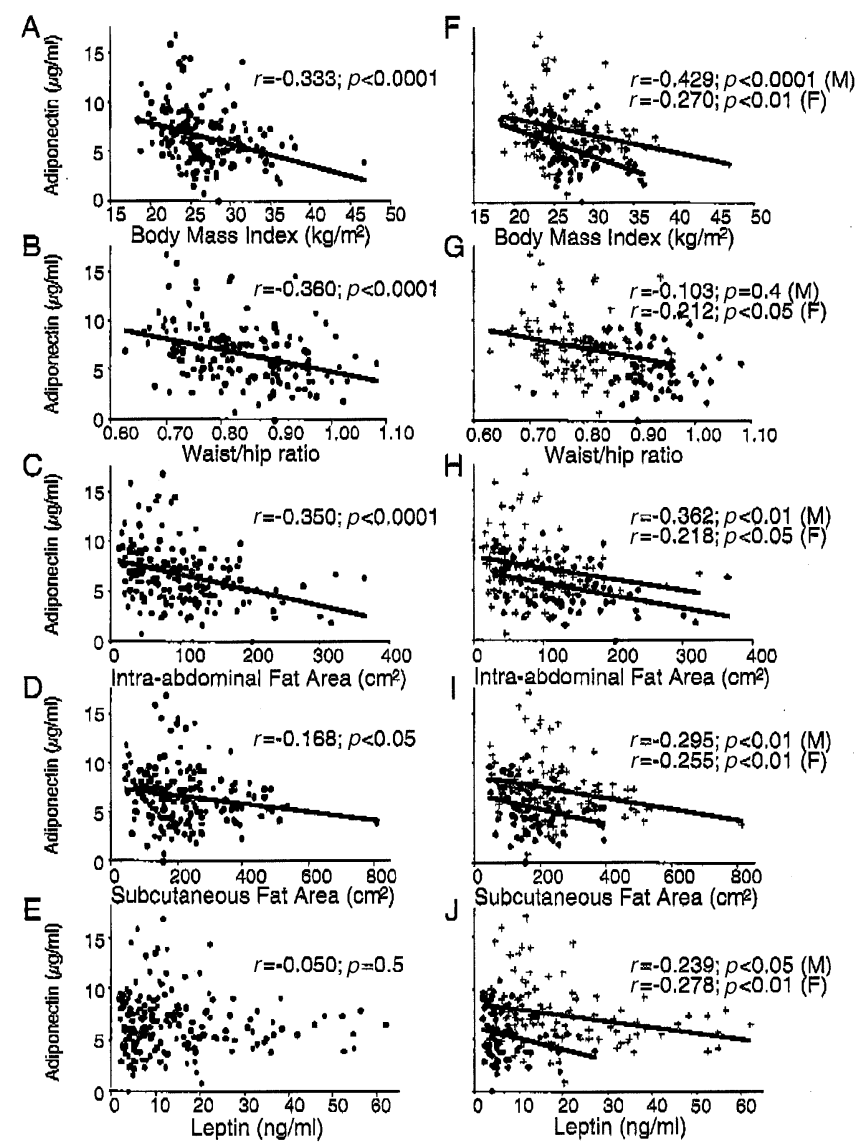

Fig. 2A-J. Relationship between adiponectin concentrations and measures of body size and body fat distribution in 182 subjects. Body size was quantified as BMI (A) while body fat distribution was quantified as waist-to-hip ratio (B), IAF area (C) and SCF area (D). The strongest correlation is with waistto-hip ratio, but this is largely the result of the sex-based difference in this ratio. These relationships between adiponectin concentrations and the measures of body size and body fat distribution are maintained when subjects are subdivided based on sex [F-I; 76 men (filled diamonds) and 106 women (crosses)], except for the relationship with waist-to-hip ratio. The relationship between adiponectin and leptin concentrations has been illustrated $(\mathbf{E})$. While no relationship is observed when the whole cohort is examined, subdivision by sex shows a relationship between the two peptides in men and women $(\mathbf{J})$

concentrations were lower. HDL cholesterol and the relative flotation index (Rf), a measure of LDL particle buoyancy, were also lower in men (Table 1).

Relationship of adiponectin concentrations with insulin sensitivity. Using the Kolmogorov-Smirnov test, adiponectin concentrations were normally distributed in this apparently healthy cohort (Fig. $4 \mathrm{~A} ; p=0.359$ ) and when men (Fig. 4B; $p=0.680$ ) and women (Fig. 4C; $p=0.096$ ) were examined separately. Insulin sensitivity, quantified as $\mathrm{S}_{\mathrm{I}}$, was positively correlated with adiponectin concentrations in the whole cohort $(r=0.375, p<0.0001$; Fig. 1A) and when examined by sex (men: $r=0.297, \quad p<0.01$; women: $r=0.410$, $p<0.0001$; Fig. 1B).
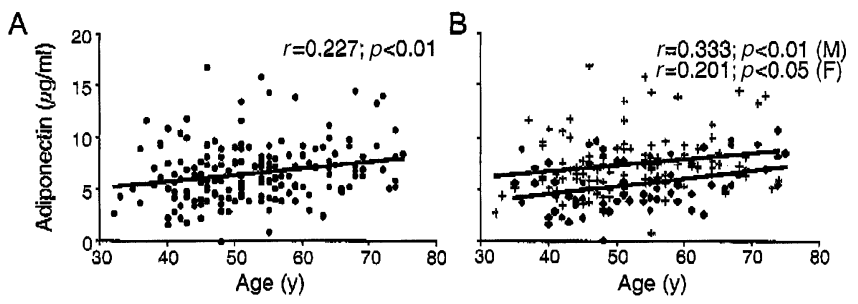

Fig. 3A, B. Relationship between adiponectin concentrations and age in 182 subjects (A). The linear correlation between these two variables is maintained when subjects are subdivided based on sex [76 men (filled diamonds)/106 women (crosses)] (B)
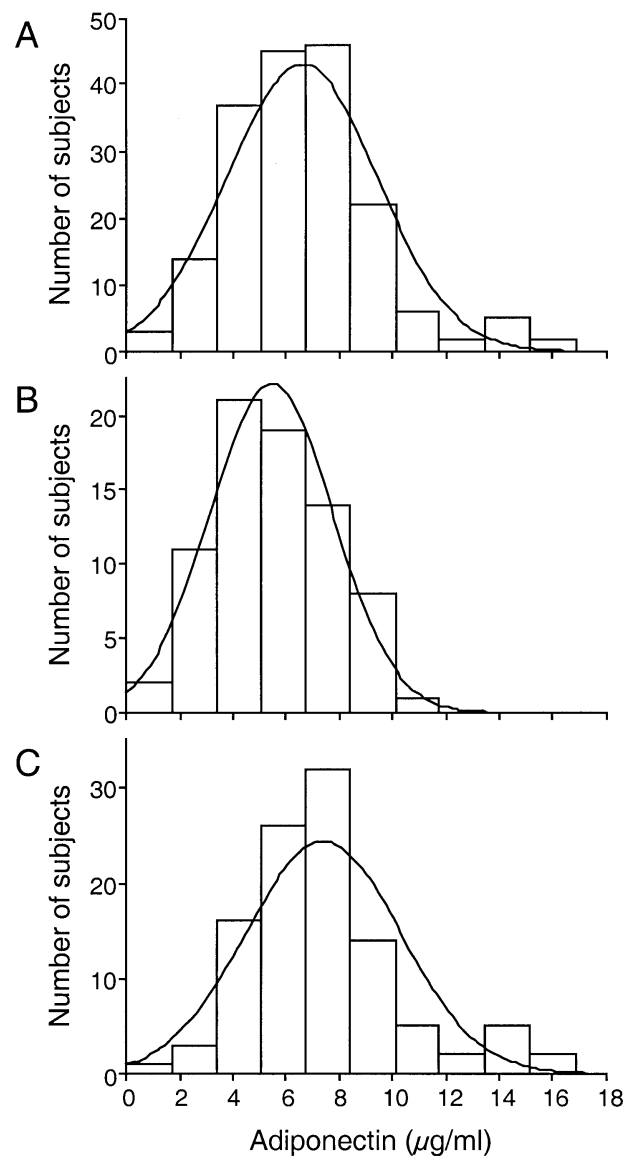

Fig. 4A-C. Distribution plots of adiponectin concentrations in all subjects (A), and in men (B) and women (C) separately. In all instances adiponectin concentrations are normally distributed ( $p$ values $0.359,0.680$ and 0.096 by the Kolmogorov-Smirnov test, respectively)

Relationship of adiponectin concentrations with body fat distribution and plasma leptin concentrations. Simple regression analysis was used to initially examine the relationship between adiponectin concentrations and body fat distribution. The relationships between adiponectin concentrations and BMI, waist-tohip ratio, and SCF and IAF areas were inverse (Fig. 2A-D). The highest correlation coefficient was 
Table 2. Body fat distribution and fasting plasma adiponectin concentrations in a subgroup of men and women matched for age and IAF area

\begin{tabular}{lcc}
\hline & Men & Women \\
\hline$n$ & 64 & 64 \\
Age $(\mathrm{y})$ & $52.8 \pm 10.4$ & $54.5 \pm 9.3$ \\
BMI $\left(\mathrm{kg} / \mathrm{m}^{2}\right)$ & $26.4 \pm 3.4$ & $27.7 \pm 4.8$ \\
Waist/hip ratio & $0.91 \pm 0.06$ & $0.80 \pm 0.06^{* *}$ \\
$\mathrm{SCF}$ area $\left(\mathrm{cm}^{2}\right)$ & $172 \pm 82$ & $288 \pm 132 * *$ \\
$\mathrm{IAF}$ area $\left(\mathrm{cm}^{2}\right)$ & $109 \pm 59$ & $106 \pm 58$ \\
$\mathrm{~S}_{\mathrm{I}}\left[\times 10^{-5} \mathrm{~min}^{-1} /(\mathrm{pmol} / \mathrm{l})\right]$ & $6.4 \pm 4.5$ & $5.8 \pm 4.0$ \\
Glucose $\left(\mathrm{mmol}^{2}\right)$ & $5.56 \pm 0.46$ & $5.35 \pm 0.44 *$ \\
Insulin $(\mathrm{pmol} / \mathrm{l})$ & $61.4 \pm 36.3$ & $71.3 \pm 43.9$ \\
Leptin $(\mathrm{ng} / \mathrm{ml})$ & $6.1 \pm 4.5$ & $22.6 \pm 13.6 * *$ \\
Adiponectin $(\mu \mathrm{g} / \mathrm{ml})$ & $5.6 \pm 2.4$ & $7.5 \pm 3.0 * *$ \\
\hline
\end{tabular}

Data are means $\pm \mathrm{SD}$

$* p<0.01, * * p<0.001$ versus men

observed for the relationship of waist-to-hip ratio with adiponectin $(r=-0.360, p<0.0001)$ followed by IAF $(r=-0.350, p<0.0001)$, BMI $(r=-0.333, p<0.0001)$, and SCF $(r=-0.168, p<0.05)$. The correlation between waist-to-hip ratio and adiponectin concentrations was largely the result of the sex-based difference in this measure of body fat distribution (Fig. 2G).

As adiponectin and leptin are both adipocyte-derived proteins, we also examined the relationship between them (Fig. 2E). Despite the fact that they are both derived from adipocytes, we did not observe a correlation between these two parameters in the whole cohort $(r=-0.05)$, although there was a negative correlation when the subjects were subdivided by sex (men: $r=-0.239, p<0.05$; women: $r=-0.278, p<0.01$; Fig. $2 \mathrm{~J}$ ).

Relationship of sex and age to adiponectin concentrations. Simple regression analyses examining the sexbased relationship between plasma adiponectin concentrations and insulin sensitivity (Fig. 1B) and body fat distribution (Fig. 2F-I) were also carried out. The slopes of the regression lines were similar, but it is apparent that women have higher adiponectin concentrations than men for similar values for each of the independent variables. The distribution plots of adiponectin concentrations (Fig. 4B, C) also illustrate that concentrations are higher in women than in men.

To examine this apparent sex difference further, we pair matched men and women for age and IAF area. We chose to match for IAF because this measure was more highly correlated with adiponectin concentrations than was SCF (Fig. 2C, D). By definition, IAF was similar in the two subgroups which were both comprised of 64 individuals (Table 2). In addition, the groups did not differ for age, BMI or insulin sensitivity. Despite these similarities, women had higher adiponectin concentrations than men, indicating a sex effect that could not be explained by the variables most strongly associated with adiponectin.
Table 3. Adiponectin concentrations, body fat distribution and metabolic characteristics of subjects, subdivided by age

\begin{tabular}{lcc}
\hline & Young & Old \\
\hline$n$ (men/women) & $94(38 / 56)$ & $88(38 / 50)$ \\
Age $(\mathrm{y})$ & $44.6 \pm 4.7$ & $61.0 \pm 6.4 * * *$ \\
BMI $\left(\mathrm{kg} / \mathrm{m}^{2}\right)$ & $26.0 \pm 3.9$ & $26.9 \pm 4.7$ \\
Waist-to-hip ratio & $0.81 \pm 0.09$ & $0.86 \pm 0.09 * * *$ \\
$\mathrm{SCF}$ area $\left(\mathrm{cm}^{2}\right)$ & $201 \pm 105$ & $236 \pm 131$ \\
$\mathrm{IAF}$ area $\left(\mathrm{cm}^{2}\right)$ & $82 \pm 55$ & $119 \pm 70^{* * *}$ \\
$\mathrm{~S}_{\mathrm{I}}\left[\times 10^{-5} \mathrm{~min}^{-1} /(\mathrm{pmol} / \mathrm{l})\right]$ & $7.1 \pm 4.3$ & $5.7 \pm 3.9 * *$ \\
Glucose $(\mathrm{mmol} / \mathrm{l})$ & $5.38 \pm 0.41$ & $5.47 \pm 0.48$ \\
Insulin $(\mathrm{pmol} / \mathrm{l})$ & $59.2 \pm 37.8$ & $68.7 \pm 49.0$ \\
Leptin $(\mathrm{ng} / \mathrm{ml})$ & $12.9 \pm 11.2$ & $15.1 \pm 13.7$ \\
Adiponectin $(\mu \mathrm{g} / \mathrm{ml})$ & $6.1 \pm 2.8$ & $7.1 \pm 2.8$ \\
\hline
\end{tabular}

Data are means \pm SD

$* p<0.05, * * p<0.01, * * * p<0.001$ vs young

To assess the relationship between age and adiponectin concentrations, we carried out simple linear regression. Interestingly, while aging is associated with an increase in IAF and a decrease in insulin sensitivity we observed an increase in adiponectin concentrations $(r=0.227, p<0.01$; Fig. 3A), which existed in both sexes (men: $r=0.333, p<0.01$; women: $r=0.201, p<0.05$; Fig. 3B).

To further examine the impact of age on adiponectin concentrations, we divided the cohort into younger ( $\leq 51$ years) and older ( $>51$ years) groups. The groups were well matched for sex but differed in age by 16 years (Table 3 ). While their BMI was similar, the older individuals had more central body fat distribution, more IAF and were more insulin resistant. Despite these differences, adiponectin concentrations were greater in the older subjects. The importance of age was even more apparent in a subgroup analysis comparing young and older subjects matched for IAF $\left(97 \pm 55 \mathrm{vs} 98 \pm 54 \mathrm{~cm}^{2}\right)$ and sex $(30 \mathrm{men} / 37$ women in each group). The two groups differed by 16 years of age $(p<0.0001)$, but had similar insulin sensitivity, BMI, waist-to-hip ratio, SCF and leptin concentrations. Nonetheless, the adiponectin concentrations were $5.5 \pm 2.8 \mu \mathrm{g} / \mathrm{ml}$ in the young subjects and $7.3 \pm 3.0 \mu \mathrm{g} / \mathrm{ml}$ in the older subgroup $(p<0.001)$.

To analyze the association between adiponectin concentrations and age, sex and measures of body fat distribution simultaneously, we carried out multiple linear regression (Table 4). Adiponectin concentrations were positively correlated with age and female gender, while the correlation with IAF was inverse. BMI and SCF did not contribute independently to the variation in adiponectin concentrations. In this regression model, the independent variables explained $29 \%$ of the variance in adiponectin concentrations. By stepwise regression analysis of the same variables, IAF accounted for $12 \%$ of the variance in adiponectin concentrations, while age and sex explained $11 \%$ and $5 \%$ 
Table 4. Multiple linear regression analysis of the relationship between adiponectin concentrations and age, sex and measures of body fat distribution

\begin{tabular}{lrll}
\hline $\begin{array}{l}\text { Independent } \\
\text { variables }\end{array}$ & Coefficient & $\begin{array}{l}\text { Standard } \\
\text { error }\end{array}$ & $p$ value \\
\hline Age & $\mathbf{0 . 0 8 4}$ & 0.019 & $<0.0001$ \\
Sex & $\mathbf{1 . 3 6 8}$ & 0.457 & 0.003 \\
BMI & -0.115 & 0.084 & 0.17 \\
SCF area & 0.001 & 0.003 & 0.77 \\
IAF area & $\mathbf{- 0 . 0 1 1}$ & 0.004 & 0.009 \\
Intercept & $\mathbf{5 . 3 3 1}$ & 2.096 & 0.01 \\
\hline
\end{tabular}

The dependent variable is adiponectin. The model $r^{2}$ is 0.287 . Sex was coded $(0,1)$ with the higher number indicating female gender. Significant regression coefficients are indicated in bold

Table 5. Multiple linear regression analysis of the relationship between $\mathrm{S}_{\mathrm{I}}$ and age, sex, measures of body fat distribution and adiponectin concentrations

\begin{tabular}{lllc}
\hline $\begin{array}{l}\text { Independent } \\
\text { variables }\end{array}$ & Coefficient & $\begin{array}{l}\text { Standard } \\
\text { error }\end{array}$ & $p$ value \\
\hline Age & -0.008 & 0.004 & 0.051 \\
Sex & -0.024 & 0.092 & 0.80 \\
BMI & -0.006 & 0.017 & 0.72 \\
SCF area & -0.001 & 0.001 & 0.12 \\
IAF area & $\mathbf{- 0 . 0 0 4}$ & 0.001 & $<0.0001$ \\
Adiponectin & $\mathbf{0 . 0 5 4}$ & 0.015 & 0.0003 \\
Intercept & $\mathbf{2 . 0 1 4}$ & 0.420 & $<0.0001$ \\
\hline
\end{tabular}

The dependent variable is $\log _{\mathrm{e}} \mathrm{S}_{\mathrm{I}}$. The model $\mathrm{r}^{2}$ is 0.479 . Sex was coded $(0,1)$ with the higher number indicating female gender. Significant regression coefficients are indicated in bold

of its variance, respectively. Thus, these analyses confirm our findings from the sex and age subgroup analyses and show that age and sex are determinants of adiponectin concentrations independent of body fat distribution.

Relationship of insulin sensitivity with body fat distribution and adiponectin concentrations. We have previously shown that IAF is the major determinant of insulin sensitivity, while BMI and SCF did not contribute independently to $S_{I}$ when examined together. To examine whether adiponectin is correlated with $S_{I}$ independently of IAF, we inserted adiponectin into the multiple regression analysis of $S_{I}$ versus age, sex and measures of body fat distribution (Table 5). By stepwise regression analysis of the same variables, IAF accounted for $41 \%$ of the variance in $\mathrm{S}_{\mathrm{I}}$, with an additional $3 \%$ being explained by adiponectin.

Relationship of plasma lipoproteins to adiponectin concentrations. The analysis of the relationships between adiponectin and lipoproteins showed that plasma adiponectin was positively correlated with HDL

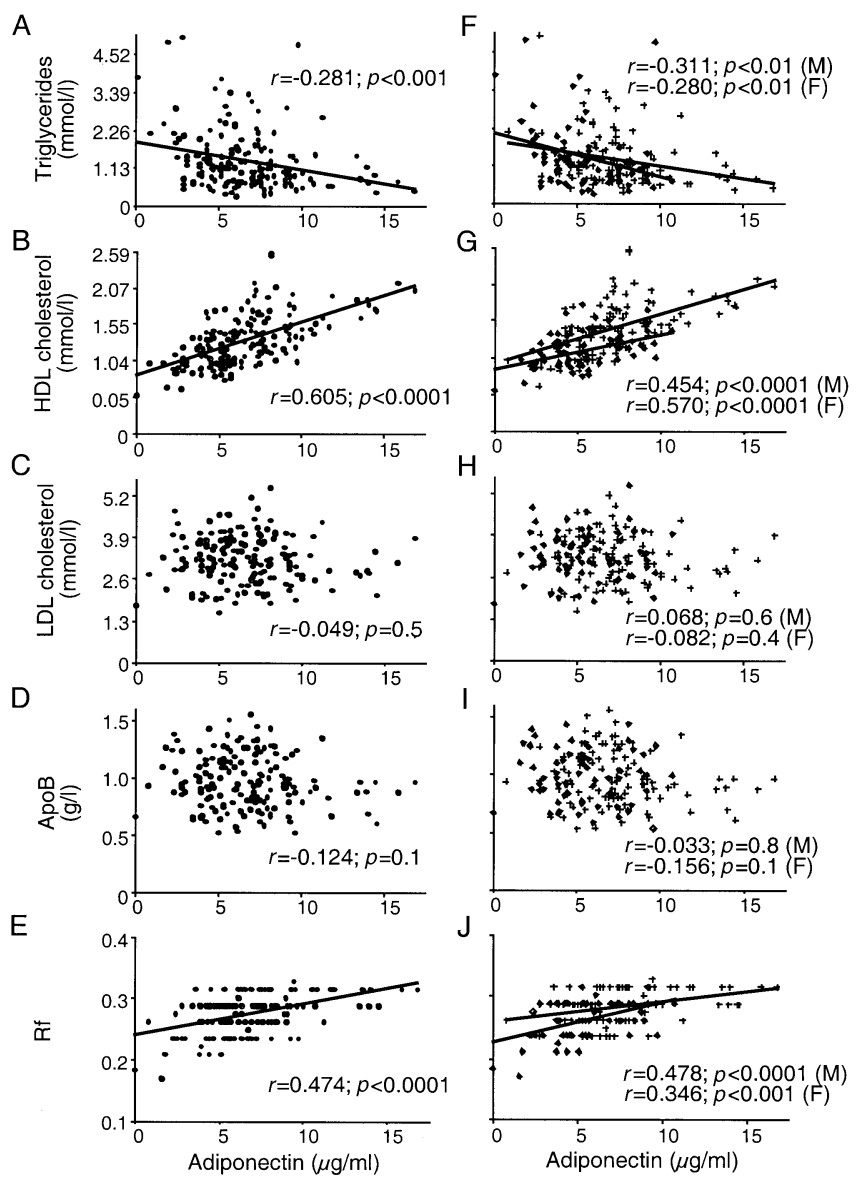

Fig. 5A-J. Relationship between plasma lipoproteins and adiponectin concentrations in 170 subjects. This relationship was examined for triglycerides (A), HDL cholesterol (B), LDL cholesterol (C) apoB (D) and the relative flotation index (Rf) as a marker of LDL buoyancy (E). Adiponectin is strongly correlated with both HDL cholesterol and Rf and is also inversely correlated with triglycerides. All these relationships are maintained when the subjects are subdivided based on $\operatorname{gender}(\mathbf{F}, \mathbf{G}, \mathbf{J})$.

cholesterol and the measure of LDL buoyancy Rf, while it was negatively correlated with plasma triglycerides (Fig. 5). No correlation was observed with LDL cholesterol or apoB. The correlation of adiponectin with HDL cholesterol was the strongest, with adiponectin explaining $37 \%$ of the variance in HDL cholesterol. These relationships were not affected by sex.

To determine whether the association between adiponectin and triglycerides, HDL cholesterol and Rf could replace body fat distribution and insulin sensitivity as predictors of these lipids, we carried out multiple linear regression analysis. Adiponectin was strongly positively correlated with HDL cholesterol and Rf, independently from IAF, which contributed to a lesser extent to these lipoproteins (Table 6). Triglycerides were also independently inversely correlated with adiponectin, although its association with IAF seemed stronger. 
Table 6. Multiple linear regression analysis of the relationship between lipoprotein concentrations and age, gender, measures of body fat distribution, insulin sensitivity and adiponectin

\begin{tabular}{|c|c|c|c|c|c|}
\hline \multirow[t]{2}{*}{ Independent variables } & \multicolumn{5}{|c|}{ Dependent variables } \\
\hline & Triglycerides & HDL cholesterol & LDL cholesterol & Apo B & $\mathrm{Rf}$ \\
\hline Age & 0.77 & 0.13 & 0.04 & 0.049 & 0.89 \\
\hline \multirow[t]{2}{*}{ Sex } & 0.177 & 0.103 & -7.720 & -0.748 & 0.037 \\
\hline & 0.07 & 0.008 & 0.15 & 0.86 & 0.07 \\
\hline \multirow[t]{2}{*}{ SCF area } & 0.001 & 0.0003 & 0.115 & 0.079 & 0.0001 \\
\hline & 0.13 & 0.26 & 0.0007 & 0.002 & 0.90 \\
\hline \multirow[t]{2}{*}{ IAF area } & 0.003 & -0.001 & 0.061 & 0.122 & -0.001 \\
\hline & 0.0003 & 0.01 & 0.23 & 0.002 & 0.003 \\
\hline \multirow[t]{2}{*}{$\mathrm{S}_{\mathrm{I}}$} & -0.024 & 0.008 & -0.845 & -0.692 & 0.004 \\
\hline & 0.21 & 0.27 & 0.42 & 0.39 & 0.35 \\
\hline
\end{tabular}

The dependent variables are $\log _{\mathrm{e}}$ triglycerides (model $\mathrm{r}^{2} 0.269$ ), $\log _{\mathrm{e}}$ HDL cholesterol (model $\mathrm{r}^{2}$ 0.508), LDL cholesterol (model $\left.r^{2} 0.153\right)$, apolipoprotein B (model $\left.r^{2} 0.245\right)$ and $\log _{e}$ Rf. (mod- el $\left.\mathrm{r}^{2} 0.355\right)$. Sex was coded $(0,1)$ with the higher number indicating female gender. Significant regression coefficients are indicated in bold and are followed by their $p$ value in italic

\section{Discussion}

Adiponectin has been postulated to be an important mediator of the interaction between adiposity and insulin sensitivity. In this large cohort of apparently healthy subjects, we examined the relationships between plasma adiponectin concentrations, insulin sensitivity, body fat distribution and plasma lipoproteins and the impact of age and sex. While our study is cross-sectional and therefore does not establish cause and effect relationships, we observed a number of interesting associations. We found that plasma adiponectin concentrations are positively correlated with insulin sensitivity while body size and intra-abdominal fat distribution are negatively related to its circulating concentrations. Further, adiponectin concentrations correlate strongly with the concentration of HDL cholesterol and LDL particle size.

It has previously been reported that insulin sensitivity based on a clamp measurement and adiponectin are related, although for analysis purposes both these variables were log transformed because their distribution was not normal [30]. In this study we have not carried out such a transformation as adiponectin concentrations were normally distributed, perhaps because our population had broad ranges of age and body anthropometry. Our finding of a positive relationship between adiponectin and insulin sensitivity supports the notion that adiponectin concentrations could modulate insulin action. This finding is supported by studies in heterozygous and homozygous adiponectin null mice which showed a dose-dependent ef- fect of adiponectin deficiency on insulin sensitivity [38]. Further, administration of adiponectin reduced insulin resistance in mice that are genetically predisposed to obesity and diabetes by enhancing fatty acid oxidation resulting in reduced circulating NEFA concentrations and tissue triglyceride content [21] and by augmenting insulin's ability to suppress hepatic glucose production $[52,53]$.

The finding of an inverse relationship between BMI and adiponectin concentrations is in keeping with previous reports in Japanese subjects [28], Pima Indians and Caucasians [30]. We have now found that central obesity and intra-abdominal fat accumulation are associated with declining adiponectin concentrations. The nature of this relationship was similar in men and women. These findings are in keeping with the recent observation that cultured adipocytes derived from the intra-abdominal fat depot secrete adiponectin more actively than subcutaneous fat derived adipocytes [54].

Our observations regarding the impact of sex suggest that adiponectin production is also related to factors independent of body fat distribution. At any particular body size or body fat distribution, adiponectin concentrations are greater in women than in men. Further, in men and women pair-matched for age, BMI, IAF and insulin sensitivity, adiponectin concentrations were greater in women. In addition, in a multiple linear regression analysis that included body size and body fat distribution, sex again had an independent effect on adiponectin concentrations. This finding of a sex-based difference in plasma adiponectin concentra- 
tions is supported by some [28, 31, 55] but not all [30, $56]$ other studies. However, the current findings are the first to account for the known sex-based differences in body fat distributions and strongly support the concept that sex has an additional independent effect to modulate adiponectin concentrations. The number of fat cells and fat cell size, both of which vary between sexes, are possible determinants of adiponectin production rates. Furthermore, it was recently reported that androgens decrease plasma adiponectin concentrations in vivo as well as adiponectin secretion from 3T3-L1 adipocytes in vitro [55].

In this cohort of subjects with a broad age range, we observed increasing adiponectin concentrations with increasing age. Normal aging is associated with the development of insulin resistance $[57,58]$ and increased fat accumulation in the central and predominantly in the intra-abdominal depot $[59,60]$. These changes would be predicted to be associated with a decline in adiponectin concentrations with age, yet we observed the opposite. Sex steroids could be responsible for some of these changes as both testosterone [55] and estrogen have been shown to inhibit adiponectin production [61] and they both decline with age. A reduction in adiponectin clearance in older individuals is another possible contributor to the agerelated increase in adiponectin. However, at this time, no information is available regarding the mechanism(s) of adiponectin clearance in humans or animals. Alternatively, our findings could also be explained by the selection of subjects in our study. If low adiponectin concentrations are predictive of the development of diabetes $[37,62]$, it is conceivable that older subjects with low adiponectin concentrations were excluded from our study because they were hyperglycaemic.

It is well recognized that dyslipidaemia is associated with central obesity and insulin resistance [63]. In this study we found that both IAF and adiponectin were major correlates of plasma lipoproteins, in particular of LDL buoyancy (Rf) and HDL cholesterol concentrations, in keeping with other reports [31, 34, 64]. These relationships could be mediated by effects of adiponectin on hepatic lipase activity, which is increased in central obesity and insulin resistance states associated with the metabolic syndrome $[65,66]$. While hepatic lipase does not seem to be acutely regulated by insulin [67], it could be increased by reduced adiponectin concentrations. The adverse lipoprotein profile is likely to be only one aspect of the cardiovascular risk associated with low adiponectin concentrations in humans. In mice, the deletion of the adiponectin gene is associated with insulin resistance and neointimal hyperplasia [38]. Further, in vitro adiponectin inhibits monocyte adhesion to endothelial cells likely by reducing the TNF- $\alpha$ mediated inflammatory response [68] and decreasing macrophage to foam cell transformation [69]. Thus, it is possible that decreased adiponectin concentrations play a critical role in the pathogenesis of atherosclerosis via various mechanisms.

Based on the findings in this study and those made by others in both humans and animals, we have developed two models to explain; (i) the regulation of adiponectin production and (ii) the effects of adiponectin on glucose and lipid metabolism. Adiponectin seems to be produced and secreted exclusively by adipocytes $[23,35,70]$, predominantly in the intra-abdominal compartment (Fig. 6A). This IAF depot is an important determinant of insulin sensitivity [11], which could in part be mediated by adiponectin's effect to enhance insulin action. Both age and female sex were independently associated with increased adiponectin concentrations. However, increasing age itself can reduce insulin sensitivity whereas female sex tends to enhance insulin sensitivity primarily by altering central body fat distribution.

IAF is a major source of adiponectin and NEFA (Fig. 6B). An increase in this fat depot will decrease adiponectin and increase NEFA, which in turn will result in an antagonism of insulin's effects in liver and peripheral tissues, primarily muscle. As adiponectin enhances insulin's effect to suppress hepatic glucose production, reduced adiponectin will decrease the effect of insulin to inhibit hepatic glucose production. In addition, we hypothesize that with low adiponectin concentrations and resultant hepatic insulin resistance, hepatic lipase activity will increase leading to a reduction in HDL cholesterol and a decrease in LDL buoyancy, two critical features of the metabolic syndrome and increased atherogenic risk. This hepatic insulin resistance and increased plasma NEFA concentrations will shift the fate of apolipoprotein B away from degradation towards secretion by the liver, resulting in increased triglyceride concentrations [20]. Finally, a reduction in adiponectin concentrations would be anticipated to impair insulin action in the peripheral tissues resulting in less efficient glucose uptake and the deposition of triglyceride in the muscle [27].

In summary, we have examined the relationship between adiponectin and body fat distribution in apparently healthy subjects and have found evidence to suggest that plasma adiponectin is more closely related to IAF than SCF and that it could be an intermediate in the relationship between visceral obesity and insulin resistance. Further, from these cross-sectional data we have found evidence that age and sex may have effects independent of IAF to determine adiponectin production. Finally, the relationship between adiponectin and plasma lipoproteins suggests that a reduction in adiponectin concentrations is associated with decreased HDL cholesterol and small dense LDL particles, an event likely mediated via an increase in hepatic lipase activity. 
A

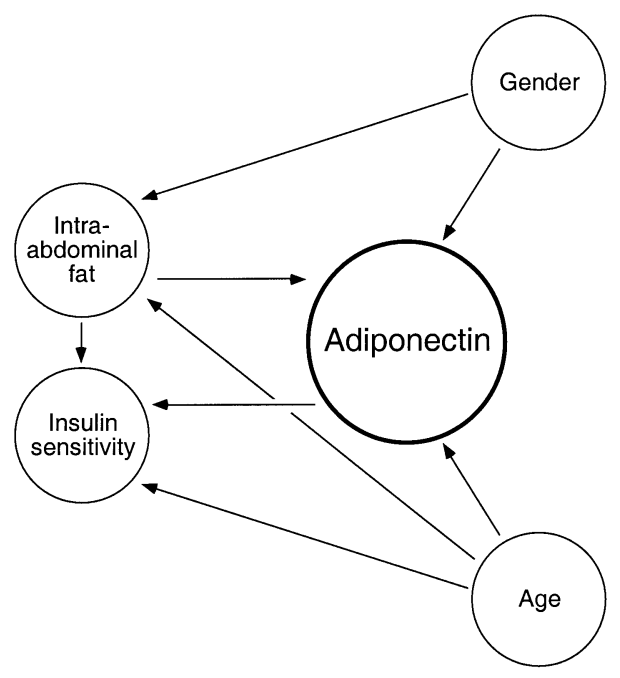

B

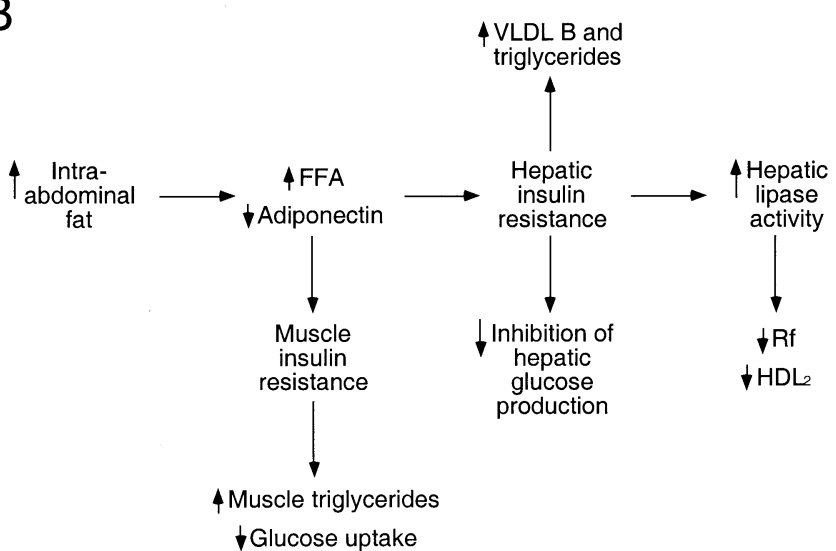

Fig. 6A, B. Models of the regulation of the production of adiponectin and its effects on glucose and lipid metabolism. (A) The predominant source of adiponectin is the intra-abdominal adipocyte. The IAF depot is an important determinant of insulin sensitivity, which could in part be mediated via adiponectin, which acts to enhance insulin sensitivity. Age and sex independently determine adiponectin levels with women having increased adiponectin concentrations, as do individuals with increasing age. In contrast to its effect to enhance adiponectin release, increasing age itself can reduce insulin sensitivity and increase IAF whereas female sex tends to favourably enhance insulin sensitivity primarily by altering central body fat distribution. (B) IAF is a major source of adiponectin and free fatty acids and increases in the volume of this fat depot will result in a decline in adiponectin and an increase in free fatty acid concentrations. The result will be an antagonism of insulin's effects in both the liver and the peripheral tissues resulting in alterations in glucose and lipid metabolism that are associated with the metabolic syndrome

Acknowledgements. We wish to thank the participants in this study without whose contribution these analyses would not have been possible. We wish to acknowledge the nursing efforts of D. Collins and the staff of the General Clinical Research Centre at the University of Washington and the data management effort of B. Fish. Dr. S. Marcovina and the staff of the Northwest Lipid Research Laboratory and the Immuno- assay Core of the Diabetes Endocrinology Research Centre are acknowledged for the performance of glucose, insulin and lipoprotein measurements and K. Stanhope and J. Graham for the leptin and adiponectin assays. This work was supported in part by the Medical Research Service of the Department of Veterans Affairs, the American Egg Board, NIH grants DK02456, DK-02654, DK-17047, DK-35747, DK-35816, DK59417, HL-30086 and RR-37, the American Diabetes Association, the U.S. Department of Agriculture, and the McMillen Family Trust. M.C. was supported by a fellowship from the Belgian American Educational Foundation.

\section{References}

1. Kolterman OG, Insel J, Saekow M, Olefsky JM (1980) Mechanisms of insulin resistance in human obesity: evidence for receptor and postreceptor defects. J Clin Invest 65:1272-1284

2. Lillioja S, Bogardus C (1988) Obesity and insulin resistance: lessons learned from the Pima Indians. Diabetes Metab Rev 4:517-540

3. Bjorntorp P (1993) Visceral obesity: a "civilization syndrome". Obes Res 1:206-222

4. Peiris AN, Mueller RA, Smith GA, Struve MF, Kissebah AH (1986) Splanchnic insulin metabolism in obesity. Influence of body fat distribution. J Clin Invest 78:1648-1657

5. Vague J (1956) The degree of masculine differentiation of obesities: a factor determining predisposition to diabetes, atherosclerosis, gout, and uric calculous disease. Am J Clin Nutr 4:20

6. Fujioka S, Matsuzawa Y, Tokunaga K, Tarui S (1987) Contribution of intra-abdominal fat accumulation to the impairment of glucose and lipid metabolism in human obesity. Metabolism 36:54-59

7. Despres JP, Nadeau A, Tremblay A et al. (1989) Role of deep abdominal fat in the association between regional adipose tissue distribution and glucose tolerance in obese women. Diabetes 38:304-309

8. Fujimoto WY, Abbate SL, Kahn SE, Hokanson JE, Brunzell JD (1994) The visceral adiposity syndrome in JapaneseAmerican men. Obes Res 2:364-371

9. Goodpaster BH, Kelley DE, Wing RR, Meier A, Thaete FL (1999) Effects of weight loss on regional fat distribution and insulin sensitivity in obesity. Diabetes 48:839-847

10. Purnell JQ, Kahn SE, Albers JJ, Nevin DN, Brunzell JD, Schwartz RS (2000) Effect of weight loss with reduction of intra-abdominal fat on lipid metabolism in older men. J Clin Endocrinol Metab 85:977-982

11. Cnop M, Landchild MJ, Vidal J et al. (2002) The concurrent accumulation of intra-abdominal and subcutaneous fat explains the association between insulin resistance and plasma leptin concentrations: distinct metabolic effects of two fat compartments. Diabetes 51:1005-1015

12. Schwartz MW, Woods SC, Porte D Jr, Seeley RJ, Baskin DG (2000) Central nervous system control of food intake. Nature 404:661-671

13. Havel PJ (2000) Role of adipose tissue in body-weight regulation: mechanisms regulating leptin production and energy balance. Proc Nutr Soc 59:359-371

14. Gordon ES (1960) Non-esterified fatty acids in blood of obese and lean subjects. Am J Clin Nutr 8:740-747

15. Boden G (1997) Role of fatty acids in the pathogenesis of insulin resistance and NIDDM. Diabetes 46:3-10

16. Shulman GI (2000) Cellular mechanisms of insulin resistance. J Clin Invest 106:171-176 
17. Arner P (1995) Differences in lipolysis between human subcutaneous and omental adipose tissues. Ann Med 27:435-438

18. Rebrin K, Steil GM, Getty L, Bergman RN (1995) Free fatty acid as a link in the regulation of hepatic glucose output by peripheral insulin. Diabetes 44:1038-1045

19. Boden G, Cheung P, Stein TP, Kresge K, Mozzoli M (2002) FFA cause hepatic insulin resistance by inhibiting insulin suppression of glycogenolysis. Am $\mathrm{J}$ Physiol 283:E12-E19

20. Fisher EA, Ginsberg HN (2002) Complexity in the secretory pathway: the assembly and secretion of apolipoprotein Bcontaining Lipoproteins. J Biol Chem 277:17377-17380

21. Fruebis J, Tsao TS, Javorschi S et al. (2001) Proteolytic cleavage product of $30-\mathrm{kDa}$ adipocyte complement-related protein increases fatty acid oxidation in muscle and causes weight loss in mice. Proc Natl Acad Sci USA 98:20052010

22. Maeda K, Okubo K, Shimomura I, Funahashi T, Matsuzawa Y, Matsubara K (1996) cDNA cloning and expression of a novel adipose specific collagen-like factor, apM1 (AdiPose Most abundant Gene transcript 1). Biochem Biophys Res Commun 221:286-289

23. Scherer PE, Williams S, Fogliano M, Baldini G, Lodish HF (1995) A novel serum protein similar to C1q, produced exclusively in adipocytes. J Biol Chem 270:26746-26749

24. Nakano Y, Tobe T, Choi-Miura NH, Mazda T, Tomita M (1996) Isolation and characterization of GBP28, a novel gelatin-binding protein purified from human plasma. J Biochem (Tokyo) 120:803-812

25. Hu E, Liang P, Spiegelman BM (1996) AdipoQ is a novel adipose-specific gene dysregulated in obesity. J Biol Chem 271:10697-10703

26. Saltiel AR (2001) You are what you secrete. Nat Med 7:887-888

27. Havel PJ (2002) Control of energy homeostasis and insulin action by adipocyte hormones: leptin, acylation stimulating protein, and adiponectin. Curr Opin Lipidol 13:51-59

28. Arita Y, Kihara S, Ouchi N et al. (1999) Paradoxical decrease of an adipose-specific protein, adiponectin, in obesity. Biochem Biophys Res Commun 257:79-83

29. Hotta K, Funahashi T, Arita Y et al. (2000) Plasma concentrations of a novel, adipose-specific protein, adiponectin, in type 2 diabetic patients. Arterioscler Thromb Vasc Biol 20:1595-1599

30. Weyer C, Funahashi T, Tanaka S et al. (2001) Hypoadiponectinemia in obesity and type 2 diabetes: close association with insulin resistance and hyperinsulinemia. J Clin Endocrinol Metab 86:1930-1935

31. Zoccali C, Mallamaci F, Tripepi G et al. (2002) Adiponectin, metabolic risk factors, and cardiovascular events among patients with end-stage renal disease. J Am Soc Nephrol 13:134-141

32. Ouchi N, Kihara S, Arita Y et al. (1999) Novel modulator for endothelial adhesion molecules: adipocyte-derived plasma protein adiponectin. Circulation 100:2473-2476

33. Stefan N, Vozarova B, Funahashi T et al. (2002) Plasma adiponectin concentration is associated with skeletal muscle insulin receptor tyrosine phosphorylation, and low plasma concentration precedes a decrease in whole-body insulin sensitivity in humans. Diabetes 51:1884-1888

34. Kazumi T, Kawaguchi A, Sakai K, Hirano T, Yoshino G (2002) Young men with high-normal blood pressure have lower serum adiponectin, smaller LDL size, and higher elevated heart rate than those with optimal blood pressure. Diabetes Care 25:971-976

35. Maeda N, Takahashi M, Funahashi T et al. (2001) PPARgamma ligands increase expression and plasma concentra- tions of adiponectin, an adipose-derived protein. Diabetes 50:2094-2099

36. Yang WS, Jeng CY, Wu TJ et al. (2002) Synthetic peroxisome proliferator-activated receptor-gamma agonist, rosiglitazone, increases plasma levels of adiponectin in type 2 diabetic patients. Diabetes Care 25:376-380

37. Hotta K, Funahashi T, Bodkin NL et al. (2001) Circulating concentrations of the adipocyte protein adiponectin are decreased in parallel with reduced insulin sensitivity during the progression to type 2 diabetes in rhesus monkeys. Diabetes 50:1126-1133

38. Kubota N, Terauchi Y, Yamauchi T et al. (2002) Disruption of adiponectin causes insulin resistance and neointimal formation. J Biol Chem 277:25863-25866

39. Maeda N, Shimomura I, Kishida K et al. (2002) Dietinduced insulin resistance in mice lacking adiponectin/ ACRP30. Nat Med 17 (online)

40. Knopp RH, Retzlaff BM, Walden CE et al. (1999) Effects of insulin resistance and obesity on the LDL response to egg ingestion. Circulation 100 (Suppl 1):I-116

41. Krotkiewski M, Bjorntorp P, Sjostrom L, Smith U (1983) Impact of obesity on metabolism in men and women. Importance of regional adipose tissue distribution. J Clin Invest 72:1150-1162

42. Shuman WP, Newell Morris LL, Leonetti DL et al. (1986) Abnormal body fat distribution detected by computed tomography in diabetic men. Invest Radiol 21:483-487

43. Schwartz RS, Shuman WP, Larson V et al. (1991) The effect of intensive endurance exercise training on body fat distribution in young and older men. Metabolism 40:545-551

44. Bergman RN, Ider YZ, Bowden CR, Cobelli C (1979) Quantitative estimation of insulin sensitivity. Am J Physiol 236:E667-E677

45. Beard JC, Bergman RN, Ward WK, Porte D Jr (1986) The insulin sensitivity index in man: correlation between clampderived and IVGTT-derived values. Diabetes 35:362-369

46. Prigeon RL, Kahn SE, Porte D Jr (1994) Reliability of error estimates from the minimal model: implications for measurements in physiological studies. Am J Physiol 266: E279-E286

47. Abbate SL, Fujimoto WY, Brunzell JD, Kahn SE (1993) Effect of heparin on insulin-glucose interactions measured by the minimal model technique: implications for reproducibility using this method. Metabolism 42:353-357

48. Morgan DR, Lazarow A (1963) Immunoassay of insulin: two antibody system: plasma insulin levels of normal, subdiabetic, and diabetic rats. Diabetes 12:115-126

49. Ma Z, Gingerich RL, Santiago JV, Klein S, Smith CH, Landt M (1996) Radioimmunoassay of leptin in human plasma. Clin Chem 42:942-946

50. Marcovina SM, Albers JJ, Kennedy H, Mei JV, Henderson LO, Hannon WH (1994) International Federation of Clinical Chemistry standardization project for measurements of apolipoproteins A-I and B. IV. Comparability of apolipoprotein B values by use of International Reference Material. Clin Chem 40:586-592

51. Purnell JQ, Marcovina SM, Hokanson JE et al. (1995) Levels of lipoprotein(a), apolipoprotein B, and lipoprotein cholesterol distribution in IDDM. Results from follow-up in the Diabetes Control and Complications Trial. Diabetes 44:1218-1226

52. Berg AH, Combs TP, Du X, Brownlee M, Scherer PE (2001) The adipocyte-secreted protein Acrp30 enhances hepatic insulin action. Nat Med 7:947-953

53. Combs TP, Berg AH, Obici S, Scherer PE, Rossetti L (2001) Endogenous glucose production is inhibited by the adiposederived protein Acrp30. J Clin Invest 108:1875-1881 
54. Motoshima H, Wu X, Sinha MK et al. (2002) Differential regulation of adiponectin secretion from cultured human omental and subcutaneous adipocytes: effects of insulin and rosiglitazone. Diabetes 51 (Suppl 2):A-88

55. Nishizawa H, Shimomura I, Kishida K et al. (2002) Androgens decrease plasma adiponectin, an insulin-sensitizing adipocyte-derived protein. Diabetes 51:2734-2741

56. Comuzzie AG, Funahashi T, Sonnenberg G et al. (2001) The genetic basis of plasma variation in adiponectin, a global endophenotype for obesity and the metabolic syndrome. J Clin Endocrinol Metab 86:4321-4325

57. DeFronzo RA (1979) Glucose intolerance of aging. Evidence for tissue insensitivity to insulin. Diabetes 28:1095-1101

58. Chen M, Bergman RN, Pacini G, Porte D Jr (1985) Pathogenesis of age-related glucose intolerance in man: insulin resistance and decreased $\beta$-cell function. J Clin Endocrinol Metab 60:13-20

59. Schwartz RS, Shuman WP, Bradbury VL et al. (1990) Body fat distribution in healthy young and older men. J Gerontol 45:M181-M185

60. Colman E, Katzel LI, Rogus E, Coon P, Muller D, Goldberg AP (1995) Weight loss reduces abdominal fat and improves insulin action in middle-aged and older men with impaired glucose tolerance. Metabolism 44:1502-1508

61. Combs TP, Berg AH, Rajala MW et al. (2003) Sexual differentiation, pregnancy, caloric restriction, and aging affect the adipocyte-specific secretory protein adiponectin. Diabetes 52:268-276

62. Lindsay RS, Funahashi T, Hanson RL et al. (2002) Adiponectin and development of type 2 diabetes in the Pima Indian population. Lancet 360:57-58
63. Brunzell JD (2003) Dyslipidemia of the metabolic syndrome. In: Eckel RH (eds) Obesity: mechanism and clinical management. Lippincott, Williams and Wilkins, Philadelphia

64. Matsubara M, Maruoka S, Katayose S (2002) Decreased plasma adiponectin concentrations in women with dyslipidemia. J Clin Endocrinol Metab 87:2764-2769

65. Despres JP, Ferland M, Moorjani S et al. (1989) Role of hepatic-triglyceride lipase activity in the association between intra-abdominal fat and plasma HDL cholesterol in obese women. Arteriosclerosis 9:485-492

66. Carr MC, Hokanson JE, Deeb SS, Purnell JQ, Mitchell ES, Brunzell JD (1999) A hepatic lipase gene promoter polymorphism attenuates the increase in hepatic lipase activity with increasing intra-abdominal fat in women. Arterioscler Thromb Vasc Biol 19:2701-2707

67. Iverius PH, Brunzell JD (1985) Human adipose tissue lipoprotein lipase: changes with feeding and relation to postheparin plasma enzyme. Am J Physiol 249:E107-E114

68. Ouchi N, Kihara S, Arita Y et al. (2000) Adiponectin, an adipocyte-derived plasma protein, inhibits endothelial NF-kappaB signaling through a cAMP-dependent pathway. Circulation 102:1296-1301

69. Ouchi N, Kihara S, Arita Y et al. (2001) Adipocyte-derived plasma protein, adiponectin, suppresses lipid accumulation and class A scavenger receptor expression in human monocyte-derived macrophages. Circulation 103:1057-1063

70. Halleux CM, Takahashi M, Delporte ML et al. (2001) Secretion of adiponectin and regulation of apM1 gene expression in human visceral adipose tissue. Biochem Biophys Res Commun 288:1102-1107 